\title{
Presence of Fusarium spp. in Air and Soil Associated with Sorghum Fields
}

Deanna L. Funnell-Harris, Grain, Forage, and Bioenergy Research Unit (GFBRU), United States Department of Agriculture-Agricultural Research Service (USDA-ARS), and Department of Plant Pathology, University of Nebraska, Lincoln 68583-0937; and Jeffrey F. Pedersen, GFBRU USDA-ARS and Department of Agronomy and Horticulture, University of Nebraska, Lincoln

\begin{abstract}
Funnell-Harris, D. L., and Pedersen, J. F. 2011. Presence of Fusarium spp. in air and soil associated with sorghum fields. Plant Dis. 95:648-656.

Sorghum grain, valuable for feed, food, and bioenergy, can be colonized by several Fusarium spp.; therefore, it was of interest to identify possible sources of conidia. Analysis of air and soil samples provided evidence for the presence of propagules from Fusarium genotypes that may cause grain infections. Soil population estimates of members of the Gibberella fujikuroi species complex, that includes sorghum pathogens and other Fusarium spp., suggested that adequate inoculum for systemic infections was present. Conidia in air samples within two sorghum fields were collected by passive trapping for 2 years. Subsampled Fusarium isolates indicated that numbers of G. fujikuroi increased

from anthesis through maturity, which coincides with grain development stages vulnerable to Fusarium spp. Genotyping using translation elongation factor $1-\alpha$ gene sequences revealed that spore trap isolates included members of $G$. fujikuroi that are sorghum pathogens: Fusarium thapsinum, $F$. verticillioides, $F$. proliferatum, and $F$. andiyazi. Also detected were $F$. graminearum, $F$. subglutinans, and several $F$. incarnatum- $F$. equiseti species complex haplotypes that colonize sorghum asymptomatically. All commonly found grain colonizers were detected from air samples in this study.
\end{abstract}

Sorghum grain is valuable for feed, food, and bioenergy. A $\mathrm{C}_{4}$ crop that is drought and heat tolerant, sorghum can be grown in tropical, subtropical, and warm-temperate climates under subsistence farming conditions (45). In the United States, grain is produced primarily for livestock feed but, in other cultures, it is a food staple (45). Because it is gluten-free and contains nutrients and protective phytochemicals unique among grasses, food-quality sorghum is produced in the United States as an alternative grain $(3,56)$. Sorghum grain can also be used in ethanol production for biofuels (59), and the distiller's grain coproduct is useable for ruminant livestock feed (1).

An advantage to growing sorghum grain for food or feed is that production of mycotoxins as a result of contaminating fungi can be considerably less than that on maize kernels $(4,7)$. This may be due to reduced total colonization by mycotoxigenic fungi (4) or lower toxin production by genotypes infecting sorghum $(11,25,35)$. Thus, sorghum grain not only has many uses, it also has the potential to be advantageous for food and feed under less-than-optimal growing or storage conditions. Nonetheless, dangerous levels of mycotoxins have resulted in sorghum, especially in stored grain (23). Natural infection of sorghum grain by Fusarium spp. can result in production of mycotoxins such as fumonisin $\mathrm{B}_{1}$, moniliformin, zearalenone, T-2, and deoxynivalenol $(7,20,27,29)$. Previously, we reported 10 Fusarium spp. or genotypes within Fusarium species complexes in grain of elite sorghum lines grown in Nebraska fields (16). Eight of these species have been reported to produce myco-

Corresponding author: D. L. Funnell-Harris,

E-mail: Deanna.Funnell-Harris@ars.usda.gov

GenBank accessions: JF270168 to JF270311.

Mention of trade names or commercial products in this article is solely for the purpose of providing specific information and does not imply recommendation or endorsement by the United States Department of Agriculture. USDA is an equal opportunity provider and employer.

Accepted for publication 5 February 2011.

doi:10.1094/PDIS-09-10-0671

This article is in the public domain and not copyrightable. It may be freely reprinted with customary crediting of the source. The American Phytopathological Society, 2011. toxins: five members of the Gibberella fujikuroi species complex, two genotypes in the Fusarium incarnatum-F. equiseti species complex (FIESC; formerly known as $F$. bullatum Sherb. and $F$. pallidoroseum (Cooke) Sacc.), and F. graminearum Schwabe. Fusarium spp. most commonly recovered are within $G$. fujikuroi (Sawada) Wollenw., particularly $F$. thapsinum Klittich, J.F. Leslie, P.E. Nelson \& Marasas (16). It is of great interest to define potential sources for Fusarium spp. colonizing sorghum grain.

Fusarium spp. are major components of the complex that causes sorghum grain mold, a disease common in humid tropical and subtropical regions $(5,54)$. It results in reduced grain yields but equally serious are affects on physical appearance and biochemical content of the grain $(54,58)$ and the presence of mycotoxins $(29)$. Sorghum is particularly vulnerable to grain mold pathogens at anthesis (flowering) through grain hard-dough stage but exposed parts of the grain can be infected until post maturity, as long as weather conditions are conducive to grain diseases and conidia of pathogens are present $(6,12,14,33,34,39,52)$. However, previous work with maize provided evidence that $F$. verticillioides (Sacc.) Nirenberg, a member of G. fujikuroi, at a low rate via systemic infection, could colonize kernels of plants grown from inoculated seed (37); it is conceivable that infected grain could also result from systemically infected plants arising from endophytically infected sorghum seed or from seedlings infected through roots by soilborne fungi. Therefore, we screened soils for Fusarium spp. from sorghum research plots and production fields in Nebraska and monitored conidia from within and above the canopies of sorghum fields, using passive spore trapping on two fungal media, throughout two growing seasons. In this way, the availability of potential inoculum in soil, that included organic matter, and in air was determined. Isolates were identified by morphological traits (soil and air) and molecular identification using the $5^{\prime}$ portion of the translation elongation factor $1-\alpha(T E F)$ gene (air) (19). In this way it was possible to determine whether infections by Fusarium spp. identified from sorghum grain grown in Nebraska could be associated with Fusarium genotypes found in soil or air.

\section{Materials and Methods}

Soil screens. Soil from sorghum research plots at the University of Nebraska, Lincoln, Field Laboratories (UNL) on the east side of Lincoln and near Ithaca, NE, was sampled pre-planting in 2005 and post harvest in 2005 and 2006. Soil also was sampled at Lincoln at harvest 2004 and one time during the winter in 2005. Fields 
at Ithaca were irrigated using an overhead sprinkler system. Soil was collected from relatively dry fields. The upper $2 \mathrm{~cm}$ of soil, which was often dry and dusty, and debris were removed and discarded from the surface; then, 0.3 to 0.4 liters of soil was collected, using a shovel, to $10 \mathrm{~cm}$ below the original soil surface. Three samples were taken randomly across each field, then combined (a total of 1.0 to 1.2 liters) and mixed. The research fields were rotated with other crops in alternate years and conventionally tilled. Following harvest, plant materials were disked into the soil during late fall if weather permitted and in the spring, prior to planting; larger plant pieces were left on the surface. The 2005 Lincoln field was in soybean-sorghum rotations since at least 2000; thus, the preplanting sample obtained in 2005 was following soybean grown during summer 2004. The 2006 Lincoln field was in corn-soybean rotation since at least 2000, with soybean planted in 2005 . The order of preceding crops for the 2005 Ithaca field was soybean (2004), sorghum (2003), soybean (2002), wheat (2001), and oat (2000); thus, the preplanting sample obtained in 2005 was following soybean grown during summer 2004. The order of preceding crops for the Ithaca field sampled in 2006 was soybean (2005), sorghum (2004), soybean (2003), wheat (2002), and oat (2001). In soybean fields at both locations, glyphosate-resistant soybean lines were planted since at least 2000 and glyphosate, a low-persistence herbicide (46), was applied at the rate of 2.25 liters $\mathrm{ha}^{-1}$. For sorghum culture, nitrogen fertilizer was applied prior to planting at both locations at $157 \mathrm{~kg} \mathrm{ha}^{-1}$. At Lincoln, propachlor (2-chloro- $N$ [1-methylethyl]- $N$-phenylacetamide) at $3.36 \mathrm{~kg} \mathrm{ha}^{-1}$ and atrazine (6-chloro- $n$-ethyl- $N^{\prime}$-[1-methylethyl]-1,3,5-triazine-2,4,diamine) at $1.1 \mathrm{~kg} \mathrm{ha}^{-1}$ were applied immediately after planting for weed control. At Ithaca, atrazine was applied at $2.2 \mathrm{~kg} / \mathrm{ha}$ immediately after planting, followed by an application of alachlor (2-chloro$2^{\prime}, 6^{\prime}$-diethyl- $N$-(methoxymethyl)acetanilide) at 4.75 liters/ha and atrazine at $1.1 \mathrm{~kg} / \mathrm{ha}$, approximately 14 days post emergence. The insecticide chlorpyrifos (phosphorothioic acid, $O, O$-diethethyl $O$ [3,4,5, trichloro-2-pyridinyl] ester) at $177 \mathrm{~g} / \mathrm{ha}$ was applied at Ithaca in 2004 for grasshopper control. Producers' fields also were sampled, two on the northwest side of Lincoln (designated NW Lincoln A and B) and one near Ruskin, NE, post harvest, during 2005 and 2006. The NW Lincoln fields were in soybean-sorghum rotation while the Ruskin field was in 2-year soybean-sorghum rotation. These fields were not irrigated. Standard commercial sorghum and soybean production practices for south-central and southeastern Nebraska were used (http://www.extension.unl.edu/ web/sorghum/home and http://www.extension.unl.edu/web/soy bean/home).

To prevent loss of culturable microorganisms, the soils were immediately processed in the following way. For each soil sample, three to six 0.90 - to 1.10 -g subsamples were assembled and sample weights were recorded; numbers of each microorganism were normalized to $1.00 \mathrm{~g}$. Each subsample was suspended in sterile purified water (Labconco, Kansas City, MO), a dilution series was prepared, and aliquots were plated onto two media. One-fifthstrength potato dextrose agar (PDA), prepared with potato dextrose broth (Becton, Dickinson and Co. [BD], Sparks, MO) and amended with $0.04 \%$ Triton X-100 (Calbiochem, EMD Biosciences, San Diego) and ampicillin at $50 \mathrm{mg} /$ liter (Sigma-Aldrich, St. Louis), was used to estimate numbers of culturable fungal and fungal-like colonies. This medium allows for growth of many culturable fungi as well as some oomycetes (32) but, because growth is confined due to the detergent, the groups are difficult to distinguish on this medium. For estimation and isolation of Fusarium spp., a semiselective peptone agar, pentachloronitrobenzene (PCNB), was used, which was amended with the fungicide Terrachlor (75\% PCNB; Uniroyal Co. Middlebury, CT) at $0.1 \%$, and streptomycin at $1 \mathrm{~g} /$ liter (Sigma-Aldrich; 38). In a previous study, approximately $60 \%$ of colonies subcultured from PCNB plates applied with soil suspensions were Fusarium isolates (17).

Plates were incubated at room temperature $\left(23^{\circ} \mathrm{C}\right)$ and fungal and oomycete colonies were enumerated 2 to 5 days following plating. From each soil, 10 to 15 single colonies were transferred from PCNB plates to one-half-strength PDA and allowed to grow 3 to 5 days at room temperature. Putative Fusarium spp. were assessed for conidia and conidiophore morphology by transferring an agar block from a PDA culture onto $1.5 \%$ agar containing $80 \mathrm{mM}$ potassium chloride and allowed to grow 5 to 7 days at room temperature. Using colony characteristics on PDA and conidia and conidiophore structures on $\mathrm{KCl}$ agar, morphological identifications were determined using the taxonomic system of Nelson et al. (40). Species within the complex G. fujikuroi, as defined by Leslie et al. (27) and O'Donnell et al. (41), were grouped together for analyses; all other Fusarium spp. were also grouped together for analyses. Genera and species outside of Fusarium that were identified through the course of the study are mentioned in the results.

Statistical analyses of soil screens. All statistical analyses were performed with SAS v. 9.1. Total fungi and oomycete numbers (CFU per gram soil) growing on each medium were not normally distributed based on Shapiro-Wilk tests for normality and were subsequently $\log$ transformed prior to analysis of variance (61). These transformed data were analyzed using PROC MIXED. Replications were treated as random variables.

For analyses of morphological identifications, total numbers of fungi collected from each location and collection time were grouped by members of G. fujikuroi species complex, other Fusarium spp., and other fungi and percentages of total fungi in each group were calculated. Each group was separately analyzed with PROC MIXED. Where the effect of year was analyzed, location was treated as a random effect. Where the effect of location was analyzed, year was treated as a random effect.

Passive spore trapping. Passive spore trapping (26) in sorghum fields was conducted throughout two growing seasons, 2005 and 2006, at UNL's field laboratories at Lincoln and Ithaca. Fields at Ithaca were irrigated, using overhead sprinklers, while those at Lincoln were not. Four collections were conducted during each season at each location, determined by plant growth stage: during vegetative growth (prior to flowering), at anthesis (defined as approximately half the plants with half the anthers exerted), during grain development, and at harvest. By necessity, passive spore traps were set on days with little or no rainfall and with wind speeds less than $4 \mathrm{~m} / \mathrm{s}$ or wind gusts less than $8 \mathrm{~m} / \mathrm{s}$. Days after planting when passive spore traps were set, plant growth stage, and weather conditions (temperature ranges, percent relative humidity, and precipitation or irrigation occurring up to 5 days prior to setting of traps) are summarized in Table 1. Passive spore traps were prepared by pouring $200 \mathrm{ml}$ of medium, either one-fifth-strength PDA with amendments or PCNB, into 150-by-25-mm round, gridded petri dishes (Integrid, Falcon; BD Labware, Franklin Lakes, $\mathrm{NJ}$ ). Four 1.8-m fiberglass ladders were set up diagonally across sorghum fields; then, a plate of each medium type was secured to ladder rungs at three heights: $0.3,0.9$, and $1.75 \mathrm{~m}$. The two lower heights were within the canopy and the upper height was above the canopy. Plates were secured using general-purpose vinyl cleanroom tape, $2.5 \mathrm{~cm}$ wide (VWR, International LLC), by taping the edge of the bottom plate, then running the tape down one side of the plate, under the ladder rung, and to the opposite side and edge of the bottom plate. Plates were covered until the start of the experiment. Media in plates were exposed by uncovering for $5 \mathrm{~min}$., $1 \mathrm{~h}, 8 \mathrm{~h}$, and $24 \mathrm{~h}$. One plate of each medium at each height was exposed for each length of time. Occasionally, plates exposed for $24 \mathrm{~h}$ and, rarely, $8 \mathrm{~h}$ were damaged due to animals, heavy dew, excessive dryness, or dust caused by nearby farming operations. Following exposure, plates were incubated in the laboratory at room temperature for 2 to 4 days, then counted, and colonies per centimeter squared per hour were determined. For each exposure time and each height, up to five colonies were transferred from PCNB plates onto one-half-strength PDA medium, then characterized as described above. Percentage of total fungi that were members of the G. fujikuroi species complex, and other Fusarium spp., as well as other fungi, were determined.

Molecular identification. Representative isolates $(n=144)$ from subsampled colonies from each PCNB plate were single-co- 
nidium purified. For each isolate, DNA was extracted from ground lyophilized mycelium (24) and the $5^{\prime}$ region of the $T E F$ gene was polymerase chain reaction (PCR) amplified using primers EF-1 and EF-2 (19). Amplification products were sequenced and sequences from opposite strands were assembled using Sequencher 4.10.1 (Gene Codes Corp., Ann Arbor, MI). Assembled sequences were compared with those in the publically available FUSARIUMID database (http://isolate.fusariumdb.org) (19). Sequences were submitted to GenBank, accession numbers JF270168 to JF270311. Sequences of some FIESC isolates and one $F$. oxysporum species complex had equivalent similarity scores to multiple haplotypes in the database; in these cases, all highly similar haplotypes were listed (e.g., 1-a,c,4-b). Genotypes of $F$. thapsinum, F. subglutinans (Wollenw. \& Reinking) P.E. Nelson, Toussoun \& Marasas, and $F$. proliferatum were defined in the following way for the current study. TEF sequences from air isolates similar to $F$. thapsinum were highly similar to Fusarium sp. isolate number 1851 (100\% similarity) and a $G$. fujikuroi isolate identified as $F$. thapsinum (99\% similarity) when compared with sequences in the FUSARIUM-ID database. When the sequences from grain isolates from a previous study were reassessed in the updated FUSARIUM-ID database, isolates previously identified as $F$. thapsinum yielded the same result (Fusarium sp. no. 1851 [100\% similarity] and G. fujikuroi anamorph $F$. thapsinum [99\% similarity]). For the purposes of this study, this group of Fusarium isolates with identical TEF genotypes will be designated as $F$. thapsinum. When TEF sequences from air isolates from the present study and grain isolates that were identified as $F$. subglutinans in a previous study $(16,17)$ were submitted to the updated FUSARIUM-ID database, they were identified as F. subglutinans or Fusarium sp. isolate number 1862, which were highly similar genotypes (near $100 \%$ similarity). Therefore, these genotypes will be designated as $F$. subglutinans for the present study. Sequences from the $T E F$ region from some air isolates were identified as being from $F$. proliferatum (Matsush.) Nirenberg ex Gerlach \& Nirenberg but a few isolates also had high similarity with the TEF sequence of Fusarium sp. isolate number 1858 (99 to $100 \%$ similarity); isolates with these $T E F$ genotypes will be referred to as $F$. proliferatum in the present study.

Statistical analyses of passive spore traps. For analysis of total number of fungal numbers growing on each medium, counts from different exposure times were standardized by calculating colonies per centimeter squared per hour. Nonparametric analyses were performed using the NPAR1WAY procedure. The SAVAGE option, recommended for exponential distributions or data with large shifts in extreme values $(21,50)$, was used to assign rank scores to individual observations. No significant differences were observed for each medium by year $(P \geq 0.40)$ or location $(P \geq 0.38)$. However, it was known that Ithaca was irrigated while Lincoln was not and that environments should be expected to be dissimilar. Therefore, results were analyzed by environment (location and year), and significant differences became apparent. For morphological identifications, total number of fungi collected from each location, collection time, and sampling height were grouped to include members of the G. fujikuroi species complex, other Fusarium spp., or other fungi and percentages of total fungi in each group were calculated. Each group was analyzed using the NPAR1WAY procedure as described above.

\section{Results}

Soil sampling. During 2005, soil samples were taken prior to planting and at harvest from fields at Lincoln and Ithaca, NE, that had been planted with soybean during the 2004 growing season. When comparing numbers of total culturable fungi and oomycetes from soil collected at the two 2005 seasons, there were significant effects of location $(P=0.05)$, season $(P<0.01)$, and their interactions $(P=0.01)$. At Lincoln, mean CFU per gram of soil declined significantly $(P<0.01)$ from $1.05 \times 10^{5}$ in the spring to $1.1 \times 10^{4}$ at harvest. At Ithaca, there were no significant differences $(P=$ 0.24 ) and the means at both seasons were $6.5 \times 10^{4} \mathrm{CFU} \mathrm{g}{ }^{-1}$ of soil. Soil also was sampled from Lincoln, at harvest 2004 and in winter and spring 2005, to determine whether total fungal and oomycete numbers can change during winter weather typically found in Nebraska. When comparing 2004 harvest and 2005 winter samples, a 2.5 fold decrease, from $3.39 \times 10^{5}$ to $1.32 \times 10^{5} \mathrm{CFU} \mathrm{g}^{-1}$ of soil, was observed $(P=0.01)$, but there was no further significant change in mean numbers in the 2005 spring sample $(P=$ 0.52). Comparisons also were made between mean numbers of total culturable fungi and oomycetes at harvest at Lincoln and Ithaca during 2005 and 2006; location and year effects were apparent $(P \leq 0.01)$ but not their interactions $(P=0.27)$. The mean numbers of culturable fungi and oomycetes at Lincoln in 2005 was $1.12 \times 10^{4}$ and in $20066.61 \times 10^{4} \mathrm{CFU} \mathrm{g^{-1 }}$ of soil whereas, at Ithaca, the 2005 and 2006 post-harvest counts were $5.01 \times 10^{4}$ and

Table 1. Temperature range and percent relative humidity $(\mathrm{RH})$ during and rainfall or irrigation 5 days prior to the 24-h time period in which passive spore traps were set

\begin{tabular}{|c|c|c|c|c|c|}
\hline Passive spore trap & DAPx & Temp. $\left({ }^{\circ} \mathbf{C}\right)^{\mathrm{y}}$ & RH (\%) & Precipitation and irrigation $(\mathrm{cm})^{\mathrm{z}}$ & Days prior to sampling \\
\hline \multicolumn{6}{|l|}{ Lincoln 2005} \\
\hline Vegetative & 56 & $26 \pm 9$ & 68.1 & 0.0 & $>5$ \\
\hline Anthesis & 71 & $21 \pm 11$ & 62.7 & 11.3 & 2 \\
\hline Grain development & 112 & $24 \pm 10$ & 71.6 & 0.2 & 1 \\
\hline Maturity & 145 & $17 \pm 13$ & 52.2 & 1.1 & 5 \\
\hline \multicolumn{6}{|l|}{ Ithaca 2005} \\
\hline Vegetative & 58 & $31 \pm 9$ & 65.4 & 2.4 & 2 \\
\hline Anthesis & 71 & $27 \pm 7$ & 69.4 & 0.1 & 0 \\
\hline Grain development & 112 & $28 \pm 9$ & 66.7 & 0.3 & 0 \\
\hline Maturity & 145 & $18 \pm 17$ & 49.7 & 0.0 & $>5$ \\
\hline \multicolumn{6}{|l|}{ Lincoln 2006} \\
\hline Vegetative & 40 & $29 \pm 8$ & 55.3 & 2.3 & 4 \\
\hline Anthesis & 60 & $22 \pm 8$ & 69.8 & 0.6 & 1 \\
\hline Grain development & 95 & $21 \pm 12$ & 64.1 & 0.0 & $>5$ \\
\hline Maturity & 141 & $11 \pm 5$ & 45.3 & 0.0 & $>5$ \\
\hline \multicolumn{6}{|l|}{ Ithaca 2006} \\
\hline Vegetative & 62 & $32 \pm 12$ & 56.6 & 0.0 & $>5$ \\
\hline Anthesis & 72 & $27 \pm 11$ & 70.0 & 3.8 & $1(\mathrm{I})$ \\
\hline \multirow[t]{2}{*}{ Grain development } & 99 & $20 \pm 11$ & 68.7 & 1.1 & 2 \\
\hline & & & & 3.8 & $4(\mathrm{I})$ \\
\hline Maturity & 162 & $10 \pm 10$ & 67.1 & 0.4 & 1 \\
\hline
\end{tabular}

${ }_{x}$ Days after planting. Fields were planted at Lincoln on 18 May 2005 and 15 June 2006 and at Ithaca on 23 May 2005 and 18 May 2006.

${ }^{y}$ Approximate temperature ranges are indicated by mean and standard deviations of high and low temperatures.

${ }^{z}$ Centimeters of precipitation or irrigation (I) 5 days or less prior to passive spore trapping are shown. Combination of $0 \mathrm{~cm}$ for "Precipitation and irrigation" and $>5$ for "Days prior to sampling" indicates that no precipitation or irrigation events had occurred for at least 5 days prior to setting passive spore traps. 
$1.32 \times 10^{5} \mathrm{CFU} \mathrm{\textrm {g } ^ { - 1 }}$ of soil, respectively. When comparing the mean numbers of culturable fungi and oomycetes at Lincoln and Ithaca with two other fields in Lincoln and a field at a distance in Ruskin, NE, again, there were location and year effects $(P \leq 0.01)$ but no effects of their interactions $(P=0.20)$. The mean fungal and oomycete CFU per gram of soil ranged from $1.23 \times 10^{4}$ at Lincoln in 2005 to $1.70 \times 10^{5}$ at NW Lincoln field A in 2006 .

When considering fungal colonies grown on Fusarium semiselective medium (PCNB) for soil collected at the two seasons during 2005, again, there were significant decreases in the number of CFU per gram of soil at both locations. Location effects were not significant $(P=0.61)$ but season effects $(P<0.01)$ and location-season interactions $(P=0.05)$ were. Mean CFU per gram of soil decreased 10-fold (from $7.94 \times 10^{4}$ to $7.24 \times 10^{3}$ ) at Lincoln and 4-fold (from $4.17 \times 10^{4}$ to $1.07 \times 10^{4}$ ) at Ithaca. When comparing mean CFU per gram of soil in samples from Lincoln and Ithaca during 2005 and 2006, selected on PCNB, year effects were observed $(P<0.01)$ but not location effects $(P=0.13)$; during 2006 , mean CFU per gram of soil was 3.5-fold higher than in 2005 (3.24 $\times 10^{4}$ versus $\left.8.91 \times 10^{3} \mathrm{CFU} \mathrm{g}^{-1}\right)$. When comparing mean CFU per gram of soil from samples from these fields, selected on PCNB, with those from two other fields in Lincoln and one near Ruskin, there were significant location and year effects $(P<0.01)$ but their interactions were not significant $(P=0.11)$. The UNL Lincoln field had significantly fewer CFU per gram of soil of colonies selected on PCNB in both years than the NW Lincoln field A $\left(7.24 \times 10^{3}\right.$ versus $1.82 \times 10^{4} \mathrm{CFU} \mathrm{g}{ }^{-1}$ for $2005[P=0.02]$ and $2.34 \times 10^{4}$ versus $9.77 \times 10^{4}$ for $\left.2006[P<0.01]\right)$ but had similar mean fungal numbers in both years to those from soil samples from NW Lincoln field B $(P \geq 0.27)$. No other comparisons of mean numbers of fungal colonies per gram of soil sampled from different fields and selected on PCNB plates were significantly different in both years.

Fungal colonies were subsampled from PCNB plates and, using morphological characteristics, were grouped as members of the $G$. fujikuroi species complex, other Fusarium spp., or other fungi. Comparing percentages of isolates collected from Lincoln or Ithaca fields at harvest in 2005 and 2006, there were no significant differences attributed to year $(P \geq 0.47)$. Therefore, results from each year were combined. Percentages of $G$. fujikuroi at the two locations $(9.5 \%$ for Lincoln and $13.0 \%$ for Ithaca; standard deviation $(\mathrm{SD})=6.9)$ and of other Fusarium spp. (67.5\% for Lincoln and $79.0 \%$ for Ithaca; $\mathrm{SD}=18.1$ ) were not significantly different at the two locations $(P \geq 0.70)$. When comparing percentages of $G$. fujikuroi and other Fusarium spp. from soils at Lincoln and Ithaca with those obtained from two fields in NW Lincoln and from the Ruskin field, there also were no significant differences $(P \geq 0.53)$.

Fusarium spp. recovered at Lincoln sorghum fields in 2005, as determined using Nelson et al. (40), were $F$. graminearum, F. merismoides Corda, F. thapsinum, and Fusarium spp. Fusarium spp. identified from 2005 Ithaca fields were $F$. aquaeductuum (Rabenh. \& Radlk.) Lagerh. \& Rabenh., F. merismoides, F. solani (Mart.) Sacc., F. subglutinans, F. thapsinum, and Fusarium spp. In 2006, F. chlamydosporum Wollenw. \& Reinking, F. equiseti (Corda) Sacc., F. lateritium Nees, F. semitectum Berk. \& Ravenel (also known as F. pallidoroseum), F. solani, and Fusarium spp. were recovered at Lincoln and $F$. anthophilum (A. Braun) Wollenw., $F$. equiseti, $F$. proliferatum, F. solani, F. verticillioides, and Fusarium spp. were found at Ithaca. Also in 2006, an Alternaria sp. was recovered at Lincoln and Microdochium nivale (Fr.) Samuels \& I.C. Hallett was recovered at Ithaca from $\mathrm{PCNB}$ plates.

At Lincoln sorghum production fields in 2005, F. merismoides, F. solani, F. thapsinum, and Fusarium spp. were obtained whereas, at Ruskin production fields, F. graminearum, F. solani, F. thapsinum, and Fusarium spp. were found. In 2006, F. avenaceum (Fr.) Sacc., F. chlamydosporum, F. equiseti, F. lateritium, F. semitectum, $F$. solani, $F$. subglutinans, $F$. thapsinum, $F$. verticillioides, and Fusarium spp. were recovered from Lincoln production fields and F. semitectum, F. solani, and F. subglutinans were found at Ruskin.

Passive spore trapping. Savage scores were generated and compared for fungal numbers (colonies per centimeter squared per hour) passively collected and grown on two media (one-fifthstrength PDA and PCNB) at four environments (Lincoln and

Table 2. Means and rank mean scores (RMS) of colonies per centimeter squared per hour as calculated from fungal colony numbers on passive spore traps on two media (potato dextrose agar [PDA] and pentachloronitrobenzene [PCNB]) exposed for different times at four environments ${ }^{\mathrm{W}}$

\begin{tabular}{|c|c|c|c|c|c|c|}
\hline \multirow[b]{2}{*}{ Exposure time } & \multicolumn{3}{|c|}{ PDA } & \multicolumn{3}{|c|}{ PCNB } \\
\hline & $N^{\mathrm{x}}$ & Mean $^{y}$ & $\mathbf{R M S}^{\mathbf{z}}$ & $N^{\mathrm{x}}$ & Mean $^{y}$ & $\mathbf{R M S}^{\mathbf{z}}$ \\
\hline \multicolumn{7}{|l|}{ Lincoln 2005} \\
\hline $5 \mathrm{~min}$ & 12 & $12.78 \pm 9.99$ & $0.7631 \mathrm{a}$ & 12 & $7.51 \pm 7.32$ & $0.5392 \mathrm{a}$ \\
\hline $1 \mathrm{~h}$ & 12 & $6.68 \pm 3.79$ & $0.0685 \mathrm{a}$ & 12 & $4.15 \pm 2.97$ & $-0.0486 \mathrm{a}$ \\
\hline $8 \mathrm{~h}$ & 12 & $3.95 \pm 2.63$ & $-0.4242 \mathrm{~b}$ & 12 & $2.97 \pm 2.16$ & $-0.2886 \mathrm{a}$ \\
\hline $24 \mathrm{~h}$ & 6 & $0.79 \pm 0.66$ & $-0.8147 \mathrm{c}$ & 3 & $0.42 \pm 0.25$ & $-0.8081 \mathrm{a}$ \\
\hline \multicolumn{7}{|l|}{ Lincoln 2006} \\
\hline $5 \mathrm{~min}$ & 12 & $18.88 \pm 14.45$ & $0.9307 \mathrm{a}$ & 12 & $7.44 \pm 8.59$ & $0.3778 \mathrm{ab}$ \\
\hline $1 \mathrm{~h}$ & 12 & $12.23 \pm 8.40$ & $0.3833 \mathrm{a}$ & 12 & $6.81 \pm 5.16$ & $0.5561 \mathrm{a}$ \\
\hline $8 \mathrm{~h}$ & 11 & $2.60 \pm 0.47$ & $-0.5070 \mathrm{~b}$ & 11 & $1.75 \pm 0.67$ & $-0.3851 \mathrm{~b}$ \\
\hline $24 \mathrm{~h}$ & 12 & $0.83 \pm 0.06$ & $-0.8493 \mathrm{c}$ & 9 & $0.59 \pm 0.31$ & $-0.7744 \mathrm{c}$ \\
\hline \multicolumn{7}{|l|}{ Ithaca 2005} \\
\hline $5 \mathrm{~min}$ & 12 & $12.11 \pm 12.78$ & $0.8486 \mathrm{a}$ & 12 & $5.90 \pm 5.86$ & $0.7106 \mathrm{a}$ \\
\hline $1 \mathrm{~h}$ & 12 & $5.36 \pm 2.60$ & $-0.0290 \mathrm{~b}$ & 12 & $2.60 \pm 1.72$ & $-0.0692 \mathrm{a}$ \\
\hline $8 \mathrm{~h}$ & 8 & $3.33 \pm 1.05$ & $-0.4531 \mathrm{~b}$ & 8 & $2.14 \pm 1.52$ & $-0.2421 \mathrm{a}$ \\
\hline $24 \mathrm{~h}$ & 7 & $1.65 \pm 0.25$ & $-0.8872 \mathrm{c}$ & 7 & $0.68 \pm 0.28$ & $-0.8114 \mathrm{~b}$ \\
\hline \multicolumn{7}{|l|}{ Ithaca 2006} \\
\hline $5 \mathrm{~min}$ & 12 & $17.37 \pm 12.23$ & $0.9714 \mathrm{a}$ & 12 & $7.46 \pm 7.67$ & $0.6201 \mathrm{ab}$ \\
\hline $1 \mathrm{~h}$ & 12 & $8.75 \pm 2.60$ & $0.3029 \mathrm{a}$ & 12 & $5.37 \pm 3.31$ & $0.2334 \mathrm{a}$ \\
\hline $8 \mathrm{~h}$ & 12 & $3.31 \pm 0.71$ & $-0.5480 \mathrm{~b}$ & 11 & $2.89 \pm 0.94$ & $-0.2241 \mathrm{~b}$ \\
\hline $24 \mathrm{~h}$ & 10 & $1.05 \pm 0.25$ & $-0.8717 \mathrm{c}$ & 10 & $0.88 \pm 0.28$ & $-0.7778 \mathrm{c}$ \\
\hline
\end{tabular}

${ }^{w}$ Counts on plates were normalized for different exposure times by calculating colonies per centimeter squared per hour. For convenience to the reader, means and standard deviations are shown. The two media were one-fifth-strength PDA and a peptone-based agar containing the fungicide PCNB. PDA allows growth of culturable fungi while PCNB is semiselective for Fusarium spp. The four environments were Lincoln, NE in 2005 and 2006 and Ithaca, NE in 2005 and 2006. Fields at Ithaca were irrigated.

${ }^{x}$ Number of observations. Some 24-h plates and a few 8-h plates were damaged due to animals, heavy dew, excessive dryness, or dust caused by nearby farming operations.

${ }^{y}$ For convenience to the reader, means (colonies per centimeter squared per hour) with standard deviations are shown.

${ }^{\mathrm{z}}$ Savage scores, generated for each exposure time of each medium at each environment, were compared using NPAR1WAY procedure (50). Pairwise comparisons were conducted between exposure times, within an environment, for colonies per centimeter squared per hour calculated from colonies on each medium. Letters next to RMS that are different indicate that $\chi^{2}$ s are significantly different at $P \leq 0.05$. 
Ithaca, 2005 and 2006). Comparisons were made for plate height in stand $(0.3,0.9$, and $1.75 \mathrm{~m})$, exposure time $(5 \mathrm{~min} ., 1 \mathrm{~h}, 8 \mathrm{~h}$, and 24 h), and plant growth stage (vegetative, anthesis, grain development, and maturity). There were no significant differences in means with regard to plate heights in each environment for colonies per centimeter squared per hour growing on PDA or PCNB $(P \geq 0.50)$. Thus, the three heights were treated as replicates for each exposure time.

Comparisons between Savage scores generated from numbers of fungi (colonies per centimeter squared per hour) collected on PDA for each exposure time showed that, for all environments, they were significantly different $(P<0.01$; Table 2$)$. The greatest numbers of colonies per centimeter squared per hour were obtained for the 5-min exposure time. Pairwise comparisons between the different exposure times showed that the 5-min and 1-h exposure times were not significantly different for colonies per centimeter squared per hour $(P \geq 0.07)$, except for the field at Ithaca, NE in 2005 ( $P=$ $0.03)$. PDA medium exposed for $24 \mathrm{~h}$ had significantly fewer colonies per centimeter squared per hour than all other exposure times $(P \leq 0.04$; Table 2).

Comparisons of Savage scores generated from numbers of fungi (colonies per centimeter squared per hour) growing on PCNB plates following each exposure time resulted in significant differences at Lincoln fields in 2006 and Ithaca in both years; exposure times at Lincoln in 2005 yielded colonies per centimeter squared per hour that were not significantly different $(P=0.07$; Table 2$)$. For all four environments, pairwise comparisons between the 5min exposure time and the 1- or 8-h exposure times showed the scores resulted with $\chi^{2}$ probabilities that were not significantly different $(P \geq 0.06)$.

For each environment, Savage scores were generated and compared for colonies per hour for sampling at each plant growth stage and for each medium. For colonies per centimeter squared per hour growing on PDA, plant growth stage was significant from both locations in $2005(P<0.01)$ but not in $2006(P \geq 0.26)$. Nonetheless, there was a trend toward increased colonies per centimeter squared per hour being collected at anthesis compared with colo- nies collected at the vegetative stage (Table 3 ). When considering colonies per centimeter squared per hour, as calculated from colonies growing on PCNB following collection at each growth stage, this trend of increasing number through the growing season was again apparent, especially at Lincoln fields in both years. At Ithaca fields, an increase was noticed at maturity in 2005 and at grain development in 2006 (Table 3).

Morphological characterization. Fungi were characterized by colony, conidia, and conidiophore morphologies and identified as belonging to one of three groups: Fusarium spp. in the G. fujikuroi species complex, other Fusarium spp., or other fungi. Savage scores were generated and compared for percentage of total fungi in each group, by environment, for height and exposure time of plate from which colonies were obtained, and plant stage at which colonies were collected. Considering each environment, each time point, and each fungal group, there were no significant differences between heights of plates within the plant stand $(P \geq 0.13)$. In only one instance did pairwise comparisons indicate a significant difference $(P=0.04)$ when comparing percentages of other fungi at the $0.3-$ and $1.75-\mathrm{m}$ heights collected at Ithaca in 2006. Because there were no significant differences in all other pairwise comparisons for the three fungal groups $(P \geq 0.07)$, plates at different heights were considered replications in other analyses.

Comparisons of Savage scores for percentage of total fungi collected from PCNB plates for each exposure time resulted in significant differences for members of the G. fujikuroi species complex at Lincoln 2006 ( $P=0.01$; Table 4$)$. The shorter exposure times of 5 min or $1 \mathrm{~h}$ resulted in percentages of G. fujikuroi isolates that were not significantly lower than one or more of the longer exposure times. With regard to percentages of total fungi that were other Fusarium spp., differences were significant for the Ithaca 2006 environment $(P=0.01)$. In this case, the 5 -min exposure time had significantly lower percentages than all other exposure times (Table 4). The percentages of total fungi that were other Fusarium spp. collected during $1-\mathrm{h}$ exposure times were similar to longer exposure times at all four environments. The Savage scores for

Table 3. Means and rank mean scores (RMS) for colonies per centimeter squared per hour calculated from fungal colonies collected as a result of passive spore trapping on two media (potato dextrose agar [PDA] and pentachloronitrobenzene [PCNB]) at four plant stages during the growing season at four environments ${ }^{\mathrm{W}}$

\begin{tabular}{|c|c|c|c|c|c|c|}
\hline \multirow[b]{2}{*}{ Plant stage } & \multicolumn{3}{|c|}{ PDA } & \multicolumn{3}{|c|}{ PCNB } \\
\hline & $N^{\mathrm{x}}$ & Mean $^{y}$ & $\mathbf{R M S}^{\mathbf{z}}$ & $N^{\mathrm{x}}$ & Mean $^{y}$ & $\mathbf{R M S}^{\mathbf{z}}$ \\
\hline \multicolumn{7}{|l|}{ Lincoln 2005} \\
\hline Vegetative & 12 & $0.75 \pm 0.69$ & $-0.8057 \mathrm{a}$ & 11 & $0.37 \pm 0.17$ & $-0.8275 \mathrm{a}$ \\
\hline Anthesis & 12 & $6.20 \pm 1.72$ & $-0.1081 \mathrm{~b}$ & 10 & $4.04 \pm 1.19$ & $-0.0973 \mathrm{~b}$ \\
\hline Grain development & 9 & $9.63 \pm 10.14$ & $0.3942 b c$ & 9 & $7.32 \pm 6.68$ & $0.4653 b c$ \\
\hline Maturity & 9 & $11.70 \pm 5.74$ & $0.6568 \mathrm{c}$ & 9 & $7.03 \pm 4.21$ & $0.5917 \mathrm{c}$ \\
\hline \multicolumn{7}{|l|}{ Lincoln 2006} \\
\hline Vegetative & 12 & $3.64 \pm 2.23$ & $-0.3833 \mathrm{a}$ & 11 & $1.13 \pm 0.98$ & $-0.5991 \mathrm{a}$ \\
\hline Anthesis & 12 & $13.51 \pm 15.75$ & $0.4016 \mathrm{a}$ & 10 & $5.39 \pm 4.73$ & $0.2007 \mathrm{~b}$ \\
\hline Grain development & 11 & $8.35 \pm 10.27$ & $-0.0505 \mathrm{a}$ & 12 & $6.51 \pm 5.70$ & $0.4261 \mathrm{~b}$ \\
\hline Maturity & 12 & $9.63 \pm 10.41$ & $0.0352 \mathrm{a}$ & 11 & $4.70 \pm 9.06$ & $-0.0506 \mathrm{ab}$ \\
\hline \multicolumn{7}{|l|}{ Ithaca 2005} \\
\hline Vegetative & 10 & $2.72 \pm 1.34$ & $-0.6206 \mathrm{a}$ & 10 & $2.09 \pm 1.95$ & $-0.3030 \mathrm{ab}$ \\
\hline Anthesis & 12 & $6.21 \pm 4.10$ & $0.1572 \mathrm{~b}$ & 11 & $2.94 \pm 1.82$ & $0.0432 \mathrm{a}$ \\
\hline Grain development & 11 & $4.08 \pm 2.31$ & $-0.3126 \mathrm{ab}$ & 12 & $1.26 \pm 0.85$ & $-0.5974 \mathrm{~b}$ \\
\hline Maturity & 6 & $17.61 \pm 16.21$ & $1.4740 \mathrm{c}$ & 6 & $8.83 \pm 7.06$ & $1.4647 \mathrm{c}$ \\
\hline \multicolumn{7}{|l|}{ Ithaca 2006} \\
\hline Vegetative & 12 & $4.24 \pm 1.93$ & -0.3506 a & 9 & $1.69 \pm 1.06$ & $-0.5601 \mathrm{a}$ \\
\hline Anthesis & 12 & $11.1 \pm 11.82$ & $0.3093 \mathrm{a}$ & 12 & $4.85 \pm 3.99$ & $0.1057 \mathrm{ab}$ \\
\hline Grain development & 12 & $9.08 \pm 8.82$ & $0.1276 \mathrm{a}$ & 12 & $7.78 \pm 7.22$ & $0.7124 \mathrm{~b}$ \\
\hline Maturity & 10 & $6.60 \pm 8.60$ & $-0.1448 \mathrm{a}$ & 12 & $2.31 \pm 1.78$ & $-0.3981 \mathrm{a}$ \\
\hline
\end{tabular}

${ }^{\mathrm{w}}$ Counts on plates were normalized for different exposure times by calculating colonies per centimeter squared per hour. For convenience to the reader, means and standard deviations are shown. The two media were one-fifth-strength PDA and a peptone-based agar containing the fungicide PCNB. PDA allows growth of culturable fungi while PCNB is semiselective for Fusarium spp. The four environments were Lincoln, NE in 2005 and 2006 and Ithaca, NE in 2005 and 2006. Fields at Ithaca were irrigated.

x Number of observations.

y For convenience to the reader, means (colonies per centimeter squared per hour) with standard deviations are shown.

${ }^{\mathrm{z}}$ Savage scores, generated for each exposure time of each medium at each environment, were compared using NPAR1WAY procedure (50). Pairwise comparisons were conducted between exposure times, within an environment, for colonies per centimeter squared per hour calculated from colonies on each medium. Letters next to rank mean scores (RMS) that are different indicate that $\chi^{2}$ s are significantly different at $P \leq 0.05$. 
other fungi were significant when considering percentages of total fungi collected during different plate exposure times for Lincoln 2005 and Ithaca $2006(P \leq 0.04)$. For the four environments, the greatest percentages of other fungi were obtained from plates exposed for $5 \mathrm{~min}$. At Lincoln in 2005, the percentage of other fungi obtained from PCNB medium exposed for $5 \min (78.5 \pm 24.9)$ was significantly greater than this percentage on plates exposed for $1 \mathrm{~h}$ ( $29.7 \pm 22.3 ; P<0.01)$; and, at Ithaca in 2006, the percentage of other fungi collected from plates exposed for $5 \mathrm{~min}(45.4 \pm 31.1)$ was significantly greater than those collected from the 1 -h $(11.7 \pm$ $19.9)$ or 24 -h $(10.0 \pm 31.6)$ exposure times $(P \leq 0.03)$.

When considering collection of fungi at each plant developmental stage, pairwise comparisons of Savage scores indicated that percentage of total fungi that were members of the G. fujikuroi species complex collected at the vegetative stage were significantly less than those for fungal isolates collected during grain development or maturity at Lincoln in $2006(P \leq 0.04)$. However, there was a trend for percentages of G. fujikuroi to be greater at grain development or maturity than during vegetative growth or at anthesis (Fig. 1). Savage scores for percentages of other Fusarium spp. were significant for Lincoln $2006(P=0.02)$ but there were no apparent trends across environments in mean percentages as suggested for G. fujikuroi isolates (Fig. 1). Mean percentages of other fungi collected from PCNB spore trap plates (semiselective for Fusarium) spp. varied widely from zero (anthesis, Lincoln 2006) to $65.6 \% \pm 31.0$ (maturity, Lincoln 2005). Savage scores of these percentages were significant for Lincoln and Ithaca in $2006(P \leq$ 0.02); however, there were no clear trends across environments. Approximately half of the other fungi recovered from the PCNB passive spore traps were in the genus Alternaria.

Molecular identification. Sequence analysis of a portion of the $T E F$ gene from representative Fusarium isolates subsampled from PCNB passive spore traps were genotyped by comparison with sequences of type isolates in the FUSARIUM-ID database (Table 5). From three environments, many of the isolates were $F$. graminearum: $49.1 \%$ at Lincoln and $25.5 \%$ at Ithaca in 2005 and $23.7 \%$ in Lincoln in 2006. Thirteen different FIESC haplotypes were detected, and genotypes in the $F$. oxysporum and $F$. solani species complexes also were detected. Four known pathogens of sorghum ( $F$. thapsinum, $F$. verticillioides, $F$. proliferatum, and Fusarium andiyazi Marasas, Rheeder, Lampr., K.A. Zeller \& J.F. Leslie) were recovered by subsampling PCNB medium, and several asymptomatic colonizers of sorghum ( $F$. subglutinans, $F$. graminearum, and members of FIESC) also were detected.

\section{Discussion}

There is an abundance of literature on airborne conidia of Fusarium spp. responsible for head blight of wheat, ear rot of maize, and pine pitch canker of Monterey pine. These studies had indicated that a warm and humid environment is important for release of spores $(18,44,51,60)$ but it also had been evident that inoculum could be detected at a range of temperatures and moisture conditions $(13,18,48,51)$. Under controlled environmental conditions, Tonapi et al. (57) determined the ideal temperature $\left(28^{\circ} \mathrm{C}\right)$ and humidity (98\%) for sporulation of an isolate of Fusarium moniliforme J. Sheld. (a complex that includes $F$. verticillioides, $F$. thapsinum, $F$. subglutinans, and $F$. proliferatum; 27$)$. In the present study, temperatures during anthesis (Lincoln 2005 and Ithaca 2005 and 2006) or grain development (Lincoln 2005 and Ithaca 2005) certainly met this ideal (Table 1) but it was unclear whether conditions, including those following rain or irrigation events, affected the number of airborne Fusarium conidia (Table 3; Figure 1). Percentage of fungal colonies that were Fusarium spp., subsampled from spore traps, tended to be greater later in the growing season: at flowering for Lincoln in 2006, during grain development for Lincoln in 2005 and Ithaca in 2006, or at grain maturity for Ithaca in 2005. Bandyopadhyay et al. (6) monitored fungal spores over a sorghum plot from anthesis until after grain maturity using an active method: a 24-h Hirst trap, which pumps in air and directs it toward a sticky microscope slide. In their study, increases in airborne Fusarium spp. later in grain development also were noticed. In the present study, passive spore traps were set and colonies were

Table 4. Means and rank mean scores (RMS) for percentage of total fungi that were members of the Gibberella fujikuroi species complex or other Fusarium spp., collected during passive spore trapping on pentachloronitrobenzene (PCNB) plates for different exposure times, during the growing season at sorghum field locations in Nebraska ${ }^{x}$

\begin{tabular}{|c|c|c|c|c|c|}
\hline \multirow[b]{2}{*}{ Exposure time } & \multirow[b]{2}{*}{$N^{\mathrm{y}}$} & \multicolumn{2}{|c|}{ G. fujikuroi (\%) } & \multicolumn{2}{|c|}{ Other Fusarium spp. (\%) } \\
\hline & & Mean & $\mathbf{R M S}^{\mathbf{z}}$ & Mean & $\mathbf{R M S}^{\mathbf{z}}$ \\
\hline \multicolumn{6}{|l|}{ Lincoln 2005} \\
\hline $5 \mathrm{~min}$ & 11 & $10.5 \pm 16.8$ & $0.0550 \mathrm{a}$ & $10.7 \pm 20.7$ & $-0.6285 b$ \\
\hline $1 \mathrm{~h}$ & 12 & $14.2 \pm 18.2$ & $0.3079 \mathrm{a}$ & $56.1 \pm 26.8$ & $0.3608 \mathrm{a}$ \\
\hline $8 \mathrm{~h}$ & 12 & $4.2 \pm 9.7$ & $-0.3012 \mathrm{a}$ & $45.0 \pm 34.6$ & $0.2423 \mathrm{a}$ \\
\hline $24 \mathrm{~h}$ & 3 & $6.7 \pm 11.5$ & $-0.2285 \mathrm{a}$ & $33.3 \pm 38.2$ & $-0.1078 \mathrm{ab}$ \\
\hline \multicolumn{6}{|l|}{ Lincoln 2006} \\
\hline $5 \min$ & 12 & $11.0 \pm 12.0$ & $-0.4742 \mathrm{c}$ & $60.3 \pm 40.5$ & $0.1975 \mathrm{a}$ \\
\hline $1 \mathrm{~h}$ & 12 & $28.6 \pm 23.6$ & $0.2440 \mathrm{ab}$ & $61.0 \pm 31.6$ & $0.0580 \mathrm{a}$ \\
\hline $8 \mathrm{~h}$ & 9 & $38.3 \pm 30.2$ & $0.7382 \mathrm{a}$ & $40.8 \pm 33.8$ & $-0.3751 \mathrm{a}$ \\
\hline $24 \mathrm{~h}$ & 10 & $12.7 \pm 13.9$ & $-0.3881 b c$ & $62.3 \pm 26.9$ & $0.0309 \mathrm{a}$ \\
\hline \multicolumn{6}{|l|}{ Ithaca 2005} \\
\hline $5 \mathrm{~min}$ & 12 & $18.3 \pm 25.1$ & $0.0393 \mathrm{a}$ & $15.8 \pm 21.0$ & $-0.4085 \mathrm{~b}$ \\
\hline $1 \mathrm{~h}$ & 12 & $14.0 \pm 16.7$ & $-0.2226 \mathrm{a}$ & $36.3 \pm 29.5$ & $0.2529 \mathrm{ab}$ \\
\hline $8 \mathrm{~h}$ & 8 & $13.1 \pm 18.7$ & $-0.1929 \mathrm{a}$ & $37.1 \pm 29.7$ & $0.3988 \mathrm{a}$ \\
\hline $24 \mathrm{~h}$ & 8 & $29.8 \pm 22.0$ & $0.4677 \mathrm{a}$ & $24.8 \pm 21.3$ & $-0.1654 \mathrm{~b}$ \\
\hline \multicolumn{6}{|l|}{ Ithaca 2006} \\
\hline $5 \mathrm{~min}$ & 12 & $30.8 \pm 18.3$ & $-0.1898 \mathrm{a}$ & $23.9 \pm 23.2$ & $-0.6067 \mathrm{c}$ \\
\hline $1 \mathrm{~h}$ & 12 & $33.6 \pm 21.1$ & $0.0347 \mathrm{a}$ & $54.8 \pm 20.6$ & $0.1122 \mathrm{ab}$ \\
\hline $8 \mathrm{~h}$ & 12 & $32.8 \pm 28.5$ & $0.2358 \mathrm{a}$ & $44.2 \pm 26.6$ & $-0.1458 \mathrm{~b}$ \\
\hline $24 \mathrm{~h}$ & 10 & $23.1 \pm 25.5$ & $-0.0969 \mathrm{a}$ & $66.9 \pm 33.7$ & $0.7684 \mathrm{a}$ \\
\hline
\end{tabular}

${ }^{\mathrm{x}}$ Fungi were grouped as members of Gibberella fujikuroi species complex, other Fusarium spp., or other fungi. For convenience to the reader, means and standard deviations are shown. PCNB is a peptone-based agar containing the fungicide PCNB and is semiselective for Fusarium spp. The four environments were Lincoln, NE in 2005 and 2006 and Ithaca, NE in 2005 and 2006. Fields at Ithaca were irrigated. Percentages of G. fujikuroi at Lincoln in 2006 and of other Fusarium spp. at Ithaca in 2006 were significant $(P=0.01)$. Percentages of other fungi also were significant at Lincoln in 2005 and Ithaca in $2006(P \leq 0.04)$ (data not shown). All other comparisons were not significant $(P \geq 0.06)$.

${ }^{y}$ Number of observations. Some 24-h plates and a few 8-h plates were damaged due to animals, heavy dew, excessive dryness, or dust caused by nearby farming operations.

${ }^{z}$ Pairwise comparisons were conducted between exposure times, within an environment, for percentage of total fungi for each fungal group. Letters next to RMS that are different indicate that $\chi^{2}$ probabilities were significantly different at $P \leq 0.05$ 
subsampled to assess morphological characteristics; then, a subset of these isolates were further genotyped using a recently available molecular technique. The relatively inexpensive use of media in passive spore trapping allowed for setting multiple traps at different locations. To assess the possibility of differential availabilities of spores at different heights within the canopy, the traps were set near the ground, at mid-plant height, and above the canopy.
Senescing lower leaves (6) as well as debris left from the previous season's crop (in this case, soybean) could act as substrate for fungal colonization and conidiation $(10,43)$. That Fusarium spp. can survive in crop residues on soil surfaces, even over harsh winters, has been well established $(31,43)$. In a study conducted in India, spore concentrations of Fusarium spp. and other fungal genera were shown to vary with distance above the ground in a sorghum
A

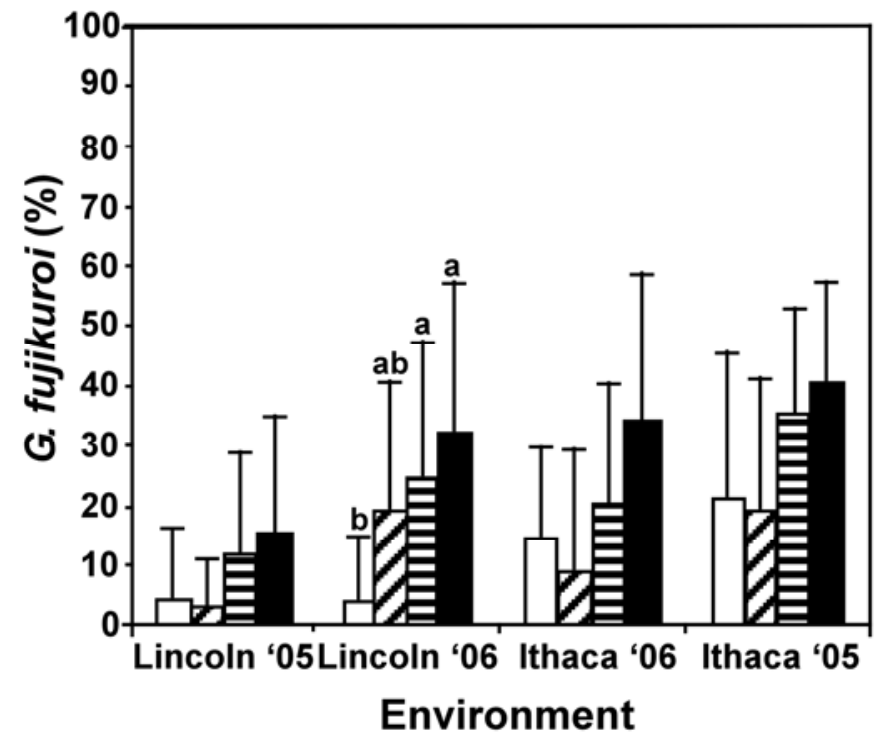

B

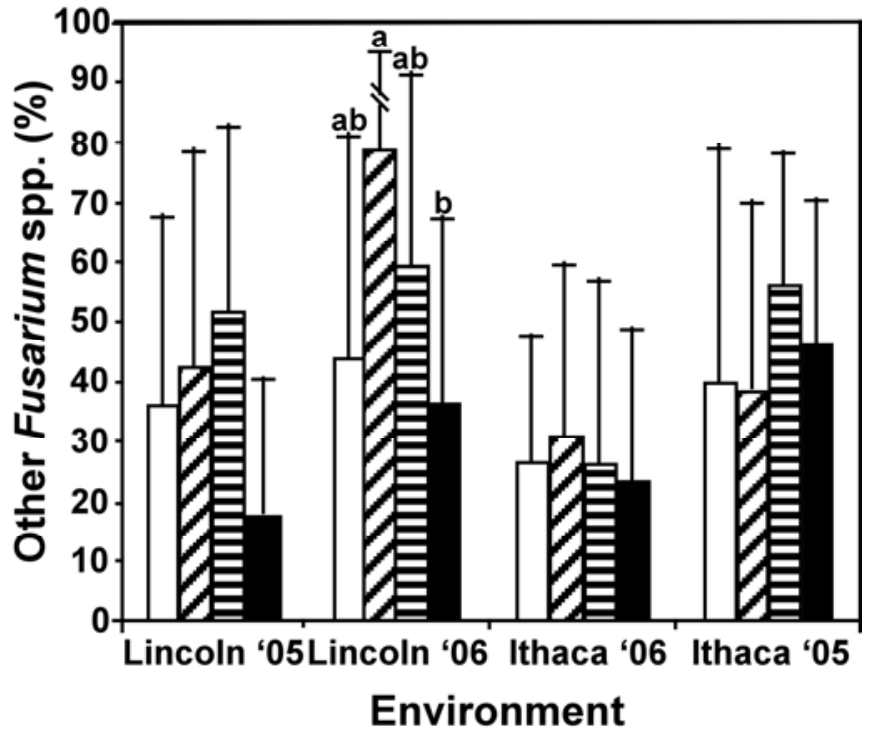

\section{$\square$ Vegetative DAnthesis 目Grain development Maturity}

Fig. 1. Percentages of fungal isolates obtained from passive spore trapping throughout the sorghum growing season at four environments, using a medium (pentachloronitrobenzene) semiselective for Fusarium spp., that were A, members of the Gibberella fujikuroi species complex as previously defined (27,41) or B, other Fusarium spp. Air samples were collected at four plant developmental stages: vegetative growth, anthesis, grain development, and maturity. Then, colonies were subsampled, genotyped by morphological characteristics, and grouped as members of the G. fujikuroi species complex, other Fusarium spp., or other fungi. Percentages of total fungi for each fungal group were compared using $\chi^{2}$ analysis of Savage scores. Means and standard deviations were calculated to construct histograms. Pairwise comparisons of Savage scores of percentages of G. fujikuroi and of other Fusarium spp. at developmental stages during passive spore trapping at Lincoln 2006, were significant $(P \leq 0.05)$ as indicated by different letters. Standard deviation of percentage of other Fusarium spp. at Lincoln 2006 during anthesis was 21.4.

Table 5. Numbers of each Fusarium genotype obtained by subsampling passive spore traps at Lincoln and Ithaca, NE in 2005 and 2006 , as indicated by sequence analysis of the translation elongation factor $1-\alpha(T E F)$ gene $^{\mathrm{w}}$

\begin{tabular}{|c|c|c|c|c|}
\hline \multirow[b]{2}{*}{ Fusarium genotype $^{\mathrm{x}}$} & \multicolumn{2}{|c|}{ Lincoln } & \multicolumn{2}{|c|}{ Ithaca } \\
\hline & 2005 & 2006 & 2005 & 2006 \\
\hline F. andiyazi* & & $1(99)$ & & $\ldots$ \\
\hline F. graminearum & $27(99-100)$ & $12(100)$ & $9(99-100)$ & \\
\hline F. proliferatum $* \mathrm{y}$ & $1(100)$ & $15(99-100)$ & $2(100)$ & $2(99-100)$ \\
\hline F. subglutinans ${ }^{\mathrm{y}}$ & $2(100)$ & $4(100)$ & & $2(100)$ \\
\hline F. thapsinum* & $\ldots$ & $4(99)$ & $3(99)$ & $1(99)$ \\
\hline F. verticillioides* & $2(100)$ & $\ldots$ & & $\ldots$ \\
\hline FIESC $1-\mathrm{a}, \mathrm{c}$ & $2(95)$ & $\ldots$ & $3(94-95)$ & $\ldots$ \\
\hline FIESC $1-\mathrm{a}, \mathrm{c} ; 4-\mathrm{b}$ & $1(94)$ & $\ldots$ & $4(94)$ & $\ldots$ \\
\hline FIESC 1-c & $1(100)$ & $\ldots$ & $7(100)$ & $\ldots$ \\
\hline FIESC $18-a, b$ & $6(100)$ & $2(100)$ & $5(100)$ & $\ldots$ \\
\hline FIESC 24-a & $1(100)$ & $\ldots$ & $1(100)$ & $\ldots$ \\
\hline FIESC $25-a, b, c$ & $3(99-100)$ & $\ldots$ & $\ldots$ & $\ldots$ \\
\hline FIESC $25-\mathrm{a}, \mathrm{b}, \mathrm{c} ; 26-\mathrm{a}, \mathrm{b}$ & $2(98)$ & $\ldots$ & $\ldots$ & $\ldots$ \\
\hline FIESC (others) & $2(99-100)$ & $1(100)$ & $3(94-99)$ & $\ldots$ \\
\hline F. oxysporum SC $216,161,51$ & $1(100)$ & & $\ldots$ & $\ldots$ \\
\hline F. solani $\mathrm{SC} 3+4 \mathrm{jj}$ & $\ldots$ & $1(100)$ & 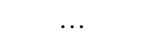 & $\ldots$ \\
\hline Fusarium sp. $(\text { no. } 1304)^{\mathrm{z}}$ & $4(99-100)$ & & $1(100)$ & $\ldots$ \\
\hline G. fujikuroi SC (no. 1857) & $\ldots$ & $7(100)$ & $\ldots$ & $1(100)$ \\
\hline
\end{tabular}

${ }^{\text {w}}$ The $5^{\prime}$ region of the TEF gene was polymerase chain reaction amplified, sequenced, and compared with sequences in the FUSARIUM-ID database to obtain molecular identifications. Percent similarity to genotype in FUSARIUM-ID database is indicated in parentheses; ... indicates that the genotype was not detected from subset of Fusarium spp. from given environment.

${ }^{\mathrm{x}}$ FIESC $=$ Fusarium incarnatum-F. equiseti species complex and SC $=$ species complex. Genotypes of FIESC that were detected only once were grouped in "others." Haplotypes of species complexes are indicated. Asterisk indicates that species is a known sorghum pathogen.

y Both F. proliferatum and F. subglutinans include two TEF genotypes each.

${ }^{\mathrm{z}}$ Number indicates isolate in FUSARIUM-ID database. 
field (55). However, in the present study, there no significant differences noticed in plates at different heights with regard to Fusarium spp.

Molecular genotyping, comparing sequences of a portion of the $T E F$ gene to those in a database (FUSARIUM-ID) (19), allowed comparison of Fusarium genotypes subsampled from passive spore traps with those that had been identified from grain (16). In a previous study, $F$. thapsinum was the predominant colonizer of grain across 3 years (2002 to 2004) and accounted for nearly 50\% of Fusarium isolates recovered from grain using PCNB selection (16). In passive air samples from the present study, F. thapsinum was detected at somewhat low levels at Lincoln in 2006 and at Ithaca during both years (Table 4). During another study of Fusarium spp. from grain sampled from plants grown at UNL fields in 2005, morphological characteristics indicated that the predominant Fusarium spp. recovered from grain at both locations was likely $F$. thapsinum (D. L. Funnell-Harris, J. F. Pedersen, and L. K. Prom, unpublished). In Nebraska, sorghum production fields are primarily found near the southern border (2), while the major crops in production near UNL research fields are corn and soybean (www.Nebraskacorn.org; http://quickstats.nass.usda.gov/). If $F$. thapsinum conidia were below the level of detection during the process of passive spore trapping and subsampling of PCNB medium, or intermittent screening did not occur on days in which $F$. thapsinum conidia were at higher levels (13), they could have been missed. Leslie and associates (28) proposed that, because $F$. thapsinum was so commonly found on sorghum and less so on other possible hosts (22), it may be specific to and aggressive on sorghum. Therefore, this apparent selection process may not require a huge abundance of inoculum. This is consistent with what we have previously observed with grain colonization by Fusarium spp.: $F$. thapsinum was frequently recovered across locations, years, and sorghum genotypes we have screened while other Fusarium spp. that commonly colonize sorghum grain could be specific to particular sorghum genotypes (16).

Fusarium isolates subsampled from passive spore traps had TEF sequences highly similar to members of the G. fujikuroi species complex, $F$. verticillioides, $F$. proliferatum, $F$. subglutinans, and $F$. andiyazi, members of the $F$. oxysporum and $F$. solani species complexes, $F$. graminearum, several FIESC haplotypes, and a few isolates designated as "Fusarium sp." in the FUSARIUM-ID database. F. verticillioides, $F$. proliferatum, $F$. subglutinans, and $F$. graminearum have been shown to be associated with ear rot diseases of maize (30); therefore, it is not surprising to recover these from passive spore traps in Lincoln and Ithaca fields. We previously reported isolating from sorghum grain Fusarium spp. with TEF genotypes of $F$. verticillioides, $F$. proliferatum, $F$. subglutinans, $F$. graminearum, and FIESC haplotypes, in addition to $F$. thapsinum (16). A reevaluation of TEF sequences from FIESC isolates from this previous study (accession numbers EF152428, GQ339783 through GQ339793 and GU116571 through GU116586) (16), using the updated FUSARIUM-ID database (42), revealed that all of the genotypes previously recovered from sorghum grain were also found on passive spore traps: 1-a, c; 1-a, c, 4-b; 24-a; 18-a, b; and 25-a, b, c (Table 5).

Members of the G. fujikuroi species complex, F. thapsinum and $F$. proliferatum, as well as other Fusarium spp., such as $F$. graminearum and members of the FIESC, are capable of infecting sorghum roots. Under environmental conditions conducive to such infections, they can result in Fusarium stalk rot disease but also can be apparently asymptomatic $(9,15,27,47)$. In maize, kernels infected with a green fluorescent protein (GFP)-marked strain of $F$. verticillioides (closely related to $F$. thapsinum) yielded plants, at a low rate, that lacked stalk disease symptoms but produced kernels with $F$. verticillioides carrying GFP (37). Thus, it is conceivable that the presence of root-infecting fungi in seeded fields might also result in systemically infected sorghum plants that yield colonized grain. By subsampling PCNB medium spread with soil suspensions and using morphological characters for identification, we can estimate that the mean populations of G. fujikuroi and other Fusa- rium spp. were $2.56 \times 10^{3}$ and $2.13 \times 10^{4} \mathrm{CFU} / \mathrm{g}$ of soil at Lincoln and $1.06 \times 10^{4}$ and $5.49 \times 10^{4} \mathrm{CFU} / \mathrm{g}$ of soil at Ithaca, respectively. It is possible that these levels of inocula may be adequate to colonize seed and seedling roots of sorghum (15). Colonization of maize seedling roots by Fusarium spp. up to 10 days after planting was associated with 4 to $17 \mathrm{CFU} / \mathrm{g}$ of soil (53) while populations of Fusarium virguliforme O'Donnell \& T. Akoi (formerly known as F. solani (Mart.) Sacc. f. sp. glycines), part of a disease complex with soybean cyst nematode, ranged from approximately 1.4 to $2.8 \times 10^{3} \mathrm{CFU} / \mathrm{g}$ of soil in fields with soybean sudden death syndrome (49).

In summary, we conducted air and soil analyses of sorghum fields in order to determine whether Fusarium spp. infecting grain might come from one of these two sources, either by direct infection of grain during development or by systemic infection via the germinating seed or roots. Members of G. fujikuroi increased after anthesis through grain maturity, which is consistent with previous reports of grain diseases of sorghum $(6,8,39)$. All Fusarium genotypes commonly identified from grain in a previous study were detected in air samples from at least one environment. Screens of soil samples from two research fields and production fields at two other locations suggested that estimated numbers of G. fujikuroi CFU per gram of soil could provide inoculum for systemic infections $(36,37)$.

\section{Acknowledgments}

We thank J. Toy and J. Rajewski for maintenance of sorghum fields at Lincoln and Ithaca; J. Toy and P. O'Neill for overseeing passive spore trapping; P. O'Neill for collection of soil samples, assisting with statistical analyses, and supervising laboratory operations; M. Pakes for laboratory assistance; members of the NE Grain Sorghum Producers board, especially J. and J. Nagel and G. Simonsen, for allowing sampling of production fields; and J. Leslie for sharing information prior to publication.

\section{Literature Cited}

1. Al-Suwaiegh, S., Fanning, K. C., Grant, R. J., Milton, C. T., and Klopfenstein, T. J. 2002. Utilization of distillers grains from the fermentation of sorghum or corn in diets for finishing beef and lactating dairy cattle. J. Anim. Sci. 80:1105-1111.

2. Anonymous. 2000. Crop profile for sorghum in Nebraska. www.ipmcenters.org.

3. Awika, J. M., and Rooney, L. W. 2004. Sorghum phytochemicals and their potential impact on human health. Phytochemistry 65:1199-1221.

4. Bandyopadhyay, R., Kumar, M., and Leslie, J. F. 2007. Relative severity of aflatoxin contamination of cereal crops of West Africa. Food Addit. Contam. 24:1109-1114.

5. Bandyopadhyay, R., Little, C. R., Waniska, R. D., and Butler, D. R. 2002. Sorghum grain mold: through the 1990s into the new millennium. Pages 172-183 in: Sorghum and Millets Diseases. J. F. Leslie, ed. Iowa State Press, Ames.

6. Bandyopadhyay, R., Muchocho, L. K., and Satyanarayana, M. V. 1991. Occurrence of airborne spores of fungi causing grain mould over a sorghum crop. Mycol. Res. 95:1315-1320.

7. Bhat, R. V., Shetty, P. H., Amruth, R. P., and Sudershan, R. V. 1997. A foodborne disease outbreak due to the consumption of moldy sorghum and maize containing fumonisin mycotoxins. Clin. Toxicol. 35:249-255.

8. Bueso, F. J., Waniska, R. D., Rooney, W. L., and Bejosano, F. P. 2000. Activity of antifungal proteins against mold in sorghum caryopses in the field. J. Agric. Food Chem. 48:810-816.

9. Claflin, L. E. 2000. Fusarium root and stalk rot. Pages 28-30 in: Compendium of Sorghum Diseases. R. A. Frederiksen and G. N. Odvody, eds. The American Phytopathological Society, St. Paul, MN.

10. Cotten, T. K., and Munkvold, G. P. 1998. Survival of Fusarium moniliforme, F. proliferatum, and F. subglutinans in maize stalk residue. Phytopathology 88:550-555.

11. da Silva, V. N., Fernandes, F. M. C., Cortez, A., Ribeiro, D. H. B., de Almeida, R. P., Hassegawa, R. H., and Correa, B. 2006. Characterization and genetic variability of Fusarium verticillioides strains isolated from corn and sorghum in Brazil based on fumonisins production, microsatellites, mating type locus, and mating crosses. Can. J. Microbiol. 52:798-804.

12. Denis, J. C., and Girard, J. C. 1980. Factors affecting the development of sorghum grain molds in Senegal. Pages 144-153 in: Proc. Int. Workshop on Sorghum Diseases. R. J. Williams, R. A. Frederiksen, and L. K. Mughogho, eds. ICRISAT, Andhra Pradesh, India.

13. Fernando, W. G. D., Miller, J. D., Seaman, W. L., Seifert, K. A., and Paulitz, T. C. 2000. Daily and seasonal dynamics of airborne spores of Fusarium graminearum and other Fusarium species sampled over wheat plots. Can. J. Bot. 78:497-505. 
14. Frederiksen, R. A., Castor, L. L., and Rosenow, D. T. 1982. Grain mold, small seed and head blight: the Fusarium connection. Pages 26-36 in: Proc. Thirty-Seventh Annu. Corn Sorghum Ind. Res. Conf. H. D. Loden and D. Wilkinson, eds. American Seed Trade Association, Washington, DC.

15. Funnell-Harris, D. L., and Pedersen, J. F. 2008. Inoculation strategies to assess biological interactions between Fusarium and Alternaria species infecting sorghum. Can. J. Plant Pathol. 30:404-413.

16. Funnell-Harris, D. L., Pedersen, J. F., and Sattler, S. E. 2010. Alteration in lignin biosynthesis restricts growth of Fusarium spp. in brown midrib sorghum. Phytopathology 100:671-681.

17. Funnell-Harris, D. L., Pedersen, J. F., and Sattler, S. E. 2010. Soil and root populations of fluorescent Pseudomonas spp. associated with seedlings and field-grown plants are affected by sorghum genotype. Plant Soil 335:439455.

18. Garbelotto, M., Smith, T., and Schweigkofler, W. 2008. Variation in rates of spore deposition of Fusarium circinatum, the causal agent of pine pitch canker, over a 12-month-period at two locations in Northern California. Phytopathology 98:137-143.

19. Geiser, D. M., del Mar Jimenez-Gasco, M., Kang, S., Makalowska, I., Veeraraghavan, N., Ward, T. J., Zhang, N., Kuldua, G. A., and O'Donnell, K. 2004. FUSARIUM-id v. 1.0: a DNA sequence database for identifying Fusarium. Eur. J. Plant Pathol. 110:473-479.

20. Hagler, W. M., Bowman, D. T., Babadoost, M., Haney, C. A., and Swanson, S. P. 1987. Aflatoxin, zearalenone, and deoxynivalenol in North Carolina grain sorghum. Crop. Sci. 27:1273-1278.

21. Hajek, J. 1969. A Course in Nonparametric Statistics. Holden-Day, San Francisco.

22. Klittich, C. J. R., Leslie, J. F., Nelson, P. E., and Marasas, W. F. O. 1997. Fusarium thapsinum (Gibberella thapsina): a new species in section Liseola from sorghum. Mycologia 89:643-652.

23. Kumar, V., Basu, M. S., and Rajendran, T. P. 2008. Mycotoxin research and mycoflora in some commercially important agricultural commodities. Crop Prot. 27:891-905

24. Lee, S. B., and Taylor, J. W. 1990. Isolation of DNA from fungal mycelia and single spores. Pages 282-287 in: PCR Protocols: a Guide to Methods and Applications. M. A. Innis, D. H. Gelfand, J. J. Sninsky, and T. J. White, eds. Harcourt, Brace Jovanovich, Publishers, San Diego, CA

25. Leslie, J. F., Plattner, R. D., Desjardins, A., and Klittich, C. J. R. 1992. Fumonisin $\mathrm{B}_{1}$ production by strains from different mating populations of Gibberella fujikuroi (Fusarium Section Liseola). Phytopathology 82:341345 .

26. Leslie, J. F., and Summerell, B. A. 2006. Techniques for recovering Fusarium. Pages 15-20 in: The Fusarium Laboratory Manual. J. F. Leslie and B. A. Summerell, eds. Blackwell, Ames, IA.

27. Leslie, J. F., Zeller, K. A., Lamprecht, S. C., Rheeder, J. P., and Marasas, W. F. O. 2005. Toxicity, pathogenicity, and genetic differentiation of five species of Fusarium from sorghum and millet. Phytopathology 95:275-283.

28. Leslie, J. F., Zeller, K. A., Logrieco, A., Mule, G., Moretti, A., and Ritieni, A. 2004. Species diversity of and toxin production by Gibberella fujikuroi species complex strains isolated from native prairie grasses in Kansas. Appl. Environ. Microbiol. 70:2254-2262.

29. Lincy, S. V., Latha, R., Chandrashekar, A., and Manonmani, H. K. 2008. Detection of toxigenic fungi and quantification of type A trichothecene levels in some food and feed materials from India. Food Control 19:962-966.

30. Logrieco, A., Mule, G., Moretti, A., and Bottalico, A. 2002. Toxigenic Fusarium species and mycotoxins associated with maize ear rot in Europe. Eur. J. Plant Pathol. 108:597-609.

31. Manzo, S. K., and Claflin, L. E. 1984. Survival of Fusarium moniliforme hyphae and conidia in grain sorghum stalks. Plant Dis. 68:866-867.

32. Mazzola, M. 1999. Transformation of soil microbial community structure and Rhizoctonia-suppressive potential in response to apple roots. Phytopathology 89:920-927.

33. Melake-Berhan, A., Butler, L. G., Ejeta, G., and Menkir, A. 1996. Grain mold resistance and polyphenol accumulation in sorghum. J. Agric. Food Chem. 44:2428-2434.

34. Menkir, A., Ejeta, G., Butler, L. G., Melakeberhan, A., and Warren, H. L. 1996. Fungal invasion of kernels and grain mold damage assessment in diverse sorghum germ plasm. Plant Dis. 80:1399-1402.

35. Moretti, A., Bennett, G. A., Logrieco, A., Bottalico, A., and Beremand, M. N. 1995. Fertility of Fusarium moniliforme from maize and sorghum related to fumonisin production in Italy. Mycopathologia 131:25-29.

36. Munkvold, G. P., McGee, D. C., and Carlton, W. M. 1997. Importance of different pathways of maize kernel infection by Fusarium moniliforme.
Phytopathology 87:209-217.

37. Murillo-Williams, A., and Munkvold, G. P. 2008. Systemic infection by Fusarium verticillioides in maize plants grown under three temperature regimes. Plant Dis. 92:1695-1700.

38. Nash, S. M., and Snyder, W. C. 1962. Quantitative estimations by plate counts of propagules of the bean root rot Fusarium in field soils. Phytopathology 52:567-572.

39. Navi, S. S., Bandyopadhyay, R., Reddy, R. K., Thakur, R. P., and Yang, X. B. 2005. Effects of wetness duration and grain development stages on sorghum grain mold infection. Plant Dis. 89:872-878.

40. Nelson, P. E., Toussoun, T. A., and Marasas, W. F. O. 1983. Fusarium Species: An Illustrated Manual for Identification. The Pennsylvania State University Press, University Park.

41. O'Donnell, K., Cigelnik, E., and Nirenberg, H. I. 1998. Molecular systematics and phylogeography of the Gibberella fujikuroi species complex. Mycologia 90:465-493.

42. O'Donnell, K., Sutton, D. A., Rinaldi, M. G., Gueidan, C., Crous, P. W., and Geiser, D. M. 2009. Novel multilocus sequence typing scheme reveals high genetic diversity of human pathogenic members of the Fusarium incarnatum- $F$. equiseti and $F$. chlamydosporum species complexes within the United States. J. Clin. Microbiol. 47:3851-3861.

43. Osborne, L. E., and Stein, J. M. 2007. Epidemiology of Fusarium head blight on small-grain cereals. Int. J. Food Microbiol. 119:103-108.

44. Parry, D. W., Jenkinson, P., and McLeod, L. 1995. Fusarium ear blight (scab) in small grain cereals-a review. Plant Pathol. 44:207-238.

45. Rai, K. N., Murty, D. S., Andrews, D. J., and Bramel-Cox, P. J. 1999. Genetic enhancement of pearl millet and sorghum for the semi-arid tropics of Asia and Africa. Genome 42:617-628.

46. Reddy, K. N. 2001. Glyphosate-resistant soybean as a weed management tool: opportunities and challenges. Weed Biol. Manage. 1:193-202.

47. Reed, J. E., and Partridge, J. E. 1983. Fungal colonization of stalks and roots of grain sorghum during the growing season. Plant Dis. 67:417-420.

48. Rossi, V., Scandolara, A., and Battilani, P. 2009. Effect of environmental conditions on spore production by Fusarium verticillioides, the causal agent of maize ear rot. Eur. J. Plant Pathol. 123:159-169.

49. Rupe, J. C., Robbins, R. T., and Gbur, E. E., Jr. 1997. Effect of crop rotation on soil population densities of Fusarium solani and Heterodera glycines and on the development of sudden death syndrome of soybean. Crop Prot. 16:575-580.

50. SAS Institute, I. 2000-2004. SAS 9.1 Help and Documentation. SAS Institute, Inc., Cary, NC

51. Schmale, D. G. I., Sheilds, E. J., and Bergstrom, G. C. 2006. Night-time spore deposition of the Fusarium head blight pathogen, Gibberella zeae, in rotational wheat fields. Can. J. Plant Pathol. 28:100-108.

52. Seitz, L. M., Mohr, H. E., Burroughs, R., and Glueck, J. A. 1983. Preharvest fungal invasion of sorghum grain. Cereal Chem. 60:127-130.

53. Soonthornpoct, P., Trevathan, L. E., and Ingram, D. 2000. The colonization of maize seedling roots and rhizosphere by Fusarium spp. in Mississippi in two soil types under conventional tillage and no-tillage systems. Phytoprotection 91:97-106.

54. Stenhouse, J. W., Bandyopadhyay, R., Singh, S. D., and Subramanian, V. 1997. Breeding for grain mold resistance in sorghum. Pages 326-336 in: Proc. Int. Conf. Genet. Improv. Sorghum and Pearl Millet. ICRISAT.

55. Subba Reddi, C., and Ramakrishna, V. 1978. Vertical profiles of spore concentration within and above a Sorghum crop. Phytopathol. Z. 93:35-40.

56. Taylor, J. R. N., Schober, R. J., and Bean, S. R. 2006. Novel food and nonfood uses for sorghum and millets. J. Cereal Sci. 44:252-271.

57. Tonapi, V. A., Mundada, R. R., Navi, S. S., Reddy, R. K., Thakur, R. P., Bandyopadhyay, R., Varanavasiappan, S., and Seetharama, N. 2007. Effect of temperature and humidity regimes on grain mold sporulation and seed quality in sorghum (Sorghum bicolor (L.) Moench). Arch. Phytopathol. Plant Prot. 40:113-127.

58. Waniska, R. D., Poe, J. H., and Bandyopadhyay, R. 1989. Effects of growth conditions on grain molding and phenols in sorghum caryopsis. J. Cereal Sci. 10:217-225

59. Wortmann, C. S., Liska, A. J., Ferguson, R. B., Lyon, D. J., Klein, R. N., and Dweikat, I. 2010. Dryland performance of sweet sorghum and grain crops for biofuel in Nebraska. Agron. J. 102:319-326.

60. Xu, X. 2003. Effects of environmental conditions on the development of Fusarium ear blight. Eur. J. Plant Pathol. 109:683-689.

61. Zuberer, D. 1994. Recovery and enumeration of viable bacteria. Pages 119144 in: Methods of Soil Analysis. Part 2, Microbiological and Biochemical Properties. R. Weaver, ed. Soil Science Society of America, Madison, WI 